\title{
Screening and follow up of an extended Hungarian family with familial medullary thyroid cancer
}

\author{
Zsuzsanna Valkusz ${ }^{1}$, Krisztian Sepp $^{1}$, Janos Gardi ${ }^{1}$, Attila Patocs ${ }^{2}$ \\ ${ }^{1}$ University of Szeged, $1^{\text {st }}$ Department of Medicine, Szeged, Hungary \\ ${ }^{2}$ Semmelweis University, $2^{\text {nd }}$ Department of Internal Medicine, Budapest, Hungary
}

\section{OBJECTIVES}

Medullary thyroid carcinoma (MTC) originates from the parafollicular or $\mathrm{C}$ cells of the thyroid gland and represents approximately $10 \%$ of all thyroid malignancies. $75 \%$ of all MTCs are believed to be sporadic, $25 \%$ correspond to familial origin. The operational classification of FMTC is four or more family members with MTC without objective evidence of pheochromocytoma (PC) and parathyroid hyperplasia. In multiple endocrine neoplasia typa 2A (MEN 2A) and familial medullary thyroid cancer (FMTC), the majority of germline mutations are restricted to specific positions in exons 10 and 11 of the RET gene. Germline mutations may very occasionally occur in other axons, including exon 14 of the RET gene. The higher level of calcitonin in the serum supports the diagnosis of MTC.

\section{METHODS}

In 2000 we reported a large kindred where the V804L mutation and the S836S variant were identified and only the V804L mutation associated with FMTC. That time 80 members of the family were evaluated. In the past 15 years the family has grown to 207 members. In our current study we summarized the follow-up data obtained in patients with RET V804L mutation of this family.

\section{Table 1: Family tree}

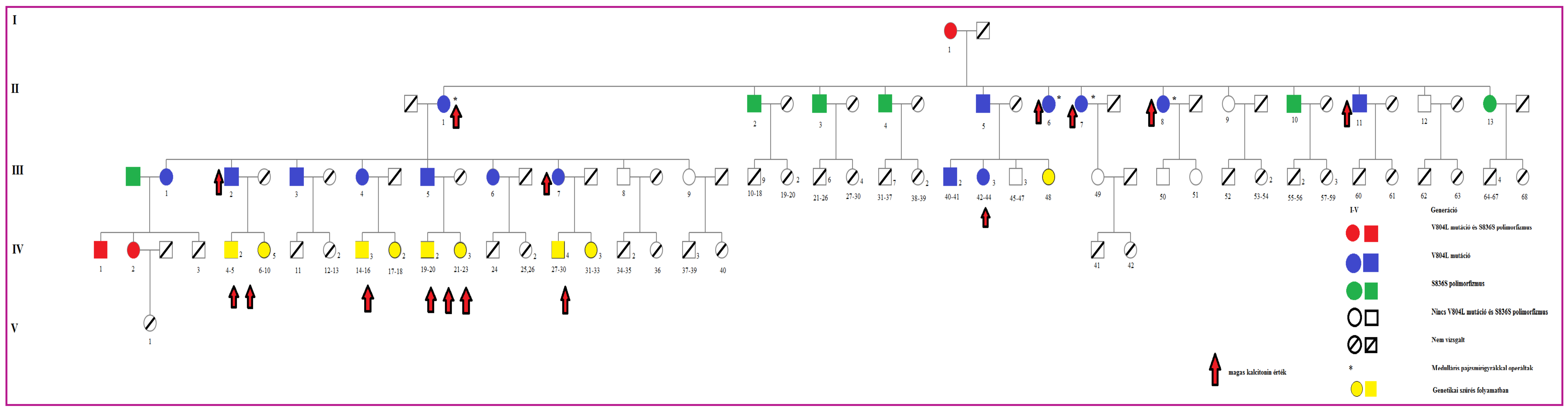

\section{RESULTS}

For the time being from 207 patients, 15 revealed V804L mutation, 5 S836S polimorfism and 3 showed up both genetic alterations. High serum calcitonin levels were found in 2 individuals of the second generation after total thyroidectomy and in two without thyroid surgery; in the third generation, 3 cases were foud with elevated calcitonin, however, the calcitonin assesment of this generation has not yet been comlpleted. In the fourth generation moderately increased calcitonin levels were demonstrated in 7 . None of the S836S polimorfisms was consistent with increased calcitonin .

\section{CONCLUSIONS}

Based on the 15 years of follow up data the cancer patients and the other mutation carriers, showed no disease progression. None of the other family members with positive genetic test had clinical or biochemical evidence of MTC. This current data confirm that the V804L mutation associates with FMTC presenting as a mild phenotype. 